\title{
Association of Conflict-Affected Environment on Ethiopian Students' Mental Health and Its Correlates During COVID-19 Era
}

\author{
Derebe Madoro' \\ Nebiyu Mengistu (D' \\ Wondwosen Molla (iD) ${ }^{2}$ \\ 'Dilla University, College of Medicine and \\ Health Science, Department of \\ Psychiatry, Dilla, Ethiopia; ${ }^{2}$ Dilla \\ University, College of Medicine and \\ Health Science, Department of \\ Midwifery, Dilla, Ethiopia
}

Background: Ethiopia has seen the largest number of conflict-induced displacement. Mental disturbance has been identified as a major public health concern among conflictaffected people, including students. Due to the effect of continuous unfold of the COVID-19 epidemic in the conflicted affected setting, the mental health problem tends to be increased. This creates a double burden for students from conflict affected setting after school reopening. As a result, the goal of this research was to evaluate the mental health impact and its correlates in students from conflict affected setting, Ethiopia.

Objective: To assess the association of conflict-affected environment on Ethiopian students' mental health and its correlates during COVID-19 era.

Methods: From April 1 to 30, 2021, an institutional-based cross-sectional survey was undertaken. A total sample of 795 students were participated through a systematic random sampling technique. The Kessler Psychological Distress Scale was used to assess mental distress (K10). The correlation between outcome and explanatory variables was investigated using bivariate and multivariate logistic regression analyses.

Results: A total of 795 people were examined, with a 100\% response rate. Mental distress was reported about $59.4 \%$ with a $95 \%$ CI of $57 \%$ to $62.9 \%$. Conflicted related sexual abuse $(\mathrm{AOR}=4.1,95 \%$ CI 2.37 to 6.94$)$, witnessed shooting $(\mathrm{AOR}=3.49,95 \%$ CI 2.7 to 5.89$)$, threat to security and safety $(\mathrm{AOR}=2.23,95 \% \mathrm{CI} 1.29$ to 3.87 ), being female (AOR $=3.01$, $95 \% \mathrm{CI} 1.61$ to 5.44 ), and poor academic performance (AOR $=2.1,95 \%$ CI 1.08 to 4.08 ) were found to be substantially correlated.

Conclusion: Students from conflict-affected areas are at high risk of mental distress. Therefore, the ministry of health, ministry of education of Ethiopia and humanitarian organizations should work collaboratively in providing consistent school-based psychosocial support and appropriate intervention for students.

Keywords: mental health, conflict affected setting, COVID 19, student, Ethiopia

\section{Introduction}

According to World Health Organization data dating from 2019, in conflict zones "one in five people live with some form of mental disorder, ranging from mild depression or anxiety to psychosis." In addition, "nearly one in ten people live with a moderate or severe mental disorder."

In 2021, nearly 50 million people were displaced worldwide because of conflict and violence but still living in their home country. Ethiopia has seen the highest number of internal displacements. According to the National Disaster and Risk
Correspondence: Derebe Madoro Dilla University, College of Medicine and Health Science, Department of Psychiatry, PO. Box 419, Dilla, Ethiopia

Email derebemd@gmail.com 
Management of Ethiopia and IDMC, a reported more than 3 million people were internally displaced due to conflict in $2021 .^{2}$

On March 13, 2020, the first case of COVID-19 in Ethiopia was verified. The Ethiopian Prime Minister's Office declared on March 16, 2020 that schools, sporting events, and public gatherings will be halted for 15 days until further notice. However, due to a heightened breakout of the virus, Ethiopia issued a state of emergency for the next five months on April 10, 2020. This has accelerated the closure of schools across the country. The Ethiopian Ministry of Health $(\mathrm{MoH})$ reported 236,554 coronavirus (COVID-19) cases and 3285 deaths in Ethiopia as of April 15, 2021. ${ }^{3}$

The Ethiopian Ministry of Education has attempted to establish techniques to resume courses at home in order to avoid the disruption of learning. ${ }^{3}$ Despite this, a study in Ethiopia revealed a poorly prepared educational system, focusing on the effects of the new coronavirus on educational provision and government initiatives to alleviate difficulties, hurdles, challenges, and opportunities to adapt to contemporary reality. ${ }^{4}$

Despite the fact that there was limited research among students from conflict-affected areas during COVID-19 in Ethiopia, various studies on the influence of the pandemic on students' mental and psychological well-being were conducted, particularly at the college and university level. For example, the psychological impact of COVID19 was $16.2 \%$ among college students, ${ }^{5}$ and the prevalence of depression, anxiety, and stress was $21.2 \%, 27.7 \%$, and $32.5 \%$, respectively, in Bench Sheko zone. ${ }^{6}$ Another study found that $22.2 \%, 39.6 \%$, and $40.2 \%$ of graduating class students had stress, anxiety, or depression, respectively. ${ }^{7}$ In a similar study, depression was reported to be $46.3 \%$, anxiety $52 \%$, and stress $28.6 \%$ prevalent, respectively. ${ }^{8}$ The overall prevalence of depression, anxiety and stress was 51\%, 51.6\% and 11.1\% recorded among Addis Ababa University students correspondingly. ${ }^{9}$

Circumstances that are or have been affected by significant disruptive conflict are referred to as conflictaffected situations (s). People in unstable and conflictaffected governments are more than three times as likely as those in other developing countries to be unable to send their children to school, according to the 2011 World Bank Development Report. Access to and completion of a primary education can be hampered in a variety of ways in unstable and conflict-affected contexts. ${ }^{10}$ 1.5 billion people live in places impacted by fragility, conflict, or large-scale, organized criminal violence. ${ }^{11}$ According to the Global Monitoring Report from that year, about 28 million primary school-aged children in conflict-affected countries were out of school. This accounts for around $42 \%$ of all out-of school children in the world. ${ }^{12}$

In armed conflict, primary school students face both direct and indirect impacts of violence, including as unlawful recruitment into armed forces, killings, genderbased violence, trafficking, and illegal detentions, as well as separation from families. ${ }^{13}$ Schoolchildren who have been exposed to conflict have higher rates of posttraumatic stress disorder, depression, and anxiety than those who have not been exposed to conflict. ${ }^{14}$ These effects are thought to be the result of both direct and indirect exposure to traumatic events, as well as elevated levels of daily stressors. ${ }^{15}$ However, mental health interventions for conflict-affected students are few, with treatment inequalities between primary school students and adults in low-resource contexts being considerably worse. $^{16}$

People (including students) who have been displaced have been exposed to many types of trauma, violence, injuries, and economic crises, rendering them more susceptible to psychological problems. ${ }^{17-19}$ Due to the effect of continuous unfold of the COVID-19 epidemic; the above problem tends to be increased. Hence, lack of family's social and economic support appears to influence academic performance of the students. ${ }^{20-24}$ This in turn exerts negative impact on mental wellbeing of students after school re-opening and school drop out more likely increased. Despite this, there are no reports on the epidemic's and conflict setting impact on students' mental wellbeing after school re-opening.

Mental distress has been identified as a major public health concern for conflict-affected populations, particularly students, and has been linked to poverty, unemployment, communal violence, unsecured living conditions, and changes in social networks. As a result, emotional discomfort is strongly linked to a lower quality of life, even after the hostility has ended and the crisis has passed. ${ }^{25,26}$ Furthermore, mental trauma can affect anyone, even students, and can have a negative impact on job performance, sleep quality, daily activities, and productivity. ${ }^{8}$ The students' ability to deal with the pandemic and to effectively and appropriately regulate their emotions and behavior during the pandemic could have 
a big impact on their long-term academic, social and mental health outcomes. ${ }^{27}$

In post-conflict and conflict-ridden societies (including students), the prevalence rate appears to be substantially greater than the overall population. ${ }^{28}$ In a variety of general population studies, statistical estimates showed that mental distress is between $1 \%$ and $5 \%,{ }^{29,30}$ and between $3 \%$ and $58 \%$ for high-risk populations, such as displaced individuals. ${ }^{31,32}$ Even though Ethiopia is one of the most highly conflict affected countries, there are no reports regarding the mental health of students from conflict affected setting after school re-opening, for instance mental distress reported within a range of $11-74 \%$ according to studies from different countries. ${ }^{9,33-36}$ The result among students in conflicted affected setting during the era of COVID-19 expected to be raised. There is no specific published study in Ethiopia, according to the investigators' knowledge. As a result, the aim of this research was to close that gap by generating new knowledge regarding the mental health of students from conflict-affected settings in Ethiopia after school re-opening.

\section{Methods}

\section{Study Design, Period, and Setting}

From April 1 to April 30, 2021, an institutional-based crosssectional survey was undertaken. During the re-opening of schools in south Ethiopia, the survey was done among students from conflict-affected areas. The study was done in two schools (2456 students were in Gedeo and 2035 students were in West Guji) located around conflict affected setting with a total of 5766 students.

\section{Study Participants and Sampling Procedure}

The respondents were chosen to use a systematic random selection procedure. Because the students were in different grade levels, proportional allocation to the number of students in each school was used to ensure that the sample was representative. The registrar provided a list of students, and participants were chosen via systematic random sampling. All level students in the conflict-affected region of south Ethiopia, located on the boundary of the Gedeo and West Guji zones, as well as those who were available during the data collection period, were included in the study. During the study period, students who were seriously unwell were excluded.

\section{Sample Size Determination}

The sample size was estimated using the single population proportion technique, with a $3 \%$ margin of error (d), a $95 \%$ confidence range of certainty (alpha $=0.05$ ), and a $10 \%$ non-response rate, assuming $\mathrm{p}=21.6 \%$ from a study done among Adama students in Ethiopia. ${ }^{36}$ A sample size of 795 was determined to be representative.

\section{Study Variables}

The dependent variable in this study was mental distress. Independent variables included socio-demographic factors (age, sex, field of study, score less than expected, residency, living with), conflicted and trauma-related factors, clinical-related factors (history of mental illness, family history of mental illness, pre-existing medical illness), and COVID-related factors (suspected/confirmed for COVID19, knowledge about COVID-19), and social support.

\section{Data Collection Procedure}

The data was collected by six BSC nurses and routinely overseen by three psychiatry professionals by using pretested questionnaires. To ensure uniformity, the questionnaire was translated into Amharic and then returned to English. Data collectors were instructed on how to conduct interviews with respondents and explain any ambiguous questions as well as the study's purpose. They were also trained on ethical standards and how to obtain respondents' informed consent for participation.

\section{Instruments}

The Kessler Psychological Distress Scale (K10) was used to assess mental distress. ${ }^{37}$ The $\mathrm{K} 10$ scale is a simple way to assess psychological distress; it consists of ten questions about emotional states, each with a five-level response scale. The K10 scale is a 10-item questionnaire that asks a person to rate their anxious and depression symptoms over the last 30 days on a 5-point Likert scale. Respondents with a score of 20 or lower were considered normal in this study, while those with a score of 20 or higher were regarded to be in emotional distress. ${ }^{38}$ At a cut-off point of $6 / 7$, it was verified with a consistency of 0.93 , a sensitivity of $84.2 \%$, and a specificity of $77.8 \%$. As a result, it was reasonable. ${ }^{39}$

Social support is measured using the Oslo-3 social support scale, which ranges from 3 to 14 . Those who score 3 to 8 are considered to have poor social support, those who score 9-11 are considered to have moderate 
social support, and those who score 12 to 14 are considered to have strong social support. ${ }^{40}$ Law achievement in this study indicates for students those scores were less than the minimum requirements during this study. Yes/no response questionnaires were used to collect data on sociodemographics, substance use history, clinical factors, COVID-19 19-related factors, and conflict and traumarelated events, which were operationalized according to various literatures.

\section{Statistical Analysis}

Epidata version 4.2 was used to clean, code, and input data, which was then exported to SPSS V.24 for analysis using descriptive methods, and the data was summarized using tables and figures. Using logistic regression analysis, associations between mental distress and related covariates were discovered. In bivariable logistic regression, variables with a $P$ value of less than two were included in the multivariable logistic regression model. A P value of less than 0.05 was considered statistically significant, and the strength of associations was determined using an adjusted odds ratio (AOR) with a $95 \%$ confidence interval (CI).

\section{Results}

\section{Socio-Demographic Characteristics of the Respondents}

A total of 795 participants took part in the study, with a $100 \%$ response rate. Males made up the majority of the 412 responders $(51.8 \%)$. The respondents' average age was $21.98( \pm 2.22)$ years. The majority of respondents $(517 \%$ or $65.1 \%)$ were from urban areas, and 354 (44.5\%) had low school achievement (Table 1).

\section{COVID Related, Clinical, Psychosocial and Behavioral Factors of Respondents}

Regarding the COVID-19-related factors, 93 (11.5\%) of respondents had a history of suspected/confirmed for COVID-19. Out of the total respondents, 17 (2.1\%) had experienced loss of family and most of the respondents 598 (75.2\%) had adequate knowledge about COVID-19. With regard to clinical characteristics, 122 (15.3\%) of the respondents had ever been treated for mental illness, and $168(21.1 \%)$ had a history of pre-existing medical illness. Of the total study participants, $150(18.9 \%)$ were current khat user. With respect to psychosocial characteristics of respondents, more than one third of respondents 306 (38.5\%) had poor social support (Table 2).

\section{Conflict and Trauma Related Factors}

Out of the total participants, $461(58 \%)$ of participants were reported fear of security and safety and $358(45 \%)$ witnessed shooting of people around them. However, more than one third $(68 \%)$ of participants family's house were destroyed during conflict (Figure 1).

\section{Prevalence of Mental Health}

The prevalence of mental distress among students from conflict affected setting was determined to be $59.4 \%$ in this study, with a $95 \%$ confidence interval of (57-62.9\%).

\section{Independent Variables Related to Mental Health}

Conflicted linked sexual abuse, witnessed shooting, threat to security and safety, being female, and having low school performance were all substantially correlated with mental distress among respondents in multivariate logistic regression, with a $\mathrm{P}$ value of 0.05 .

When compared to their counterparts, those who had suffered conflict-related sexual abuse were 4.1 times more likely to suffer from mental distress (AOR $=4.1,95 \% \mathrm{CI}$ 2.37 to 6.94$)$. When compared to their counterparts, those who watched persons being shot during a conflict or war were 3.49 times more likely to acquire mental distress (AOR $=4.1,95 \%$ CI 2.37 to 6.94$)$. When compared to those who had no fear of security and safety in the school environment, those who had felt fear of security and safety were 2.23 times more likely to suffer mental distress (AOR $=2.23,95 \%$ CI 1.29 to 3.87 ). The risk of developing mental distress was two times higher in participants with poor school achievement $(\mathrm{AOR}=2.1,95 \%$ CI 1.08 to 4.08). Females were 3.01 times more likely than males to experience mental distress $(\mathrm{AOR}=3.01,95 \% \mathrm{CI} 1.61$ to 5.44) (Table 3).

\section{Discussion}

The prevalence of mental distress was found to be $57.4 \%$ (95\% CI 57 to 62.9) among Ethiopian students from conflict-affected areas, according to the findings of this study. This study's prevalence matches that of research conducted in Saudi Arabia (58.1\%), ${ }^{8}$ Pakistan 57.6\%. ${ }^{41}$ On the other hand, the current study's findings were lower than those of a Pakistani study, which came in at $68.4 .^{42}$ The gap could be due to a methodological variation in how an online cross-sectional survey was carried out in Pakistan; the results could be more skewed and subjective 
Table I Distribution of Socio-Demographic Factors Among Students from Conflict Affected Setting in South Ethiopia, 202I $(n=795)$

\begin{tabular}{|c|c|c|}
\hline Variables & Frequency (n) & Percent (\%) \\
\hline \multicolumn{3}{|l|}{ Age } \\
\hline $15-19$ years old & 403 & 50.6 \\
\hline 20-24 years old & 238 & 29.9 \\
\hline$\geq 25$ years old & 154 & 19.3 \\
\hline \multicolumn{3}{|l|}{ Sex } \\
\hline Male & 412 & 51.8 \\
\hline Female & 383 & 48.2 \\
\hline \multicolumn{3}{|l|}{ Religion } \\
\hline Orthodox & 117 & 14.7 \\
\hline Protestant & 588 & 73.9 \\
\hline Catholic & 74 & 9.3 \\
\hline Muslim & II & 1.4 \\
\hline Other* & 5 & 0.6 \\
\hline \multicolumn{3}{|l|}{ Class level } \\
\hline 7th grade & 272 & 34.2 \\
\hline 8th grade & 238 & 29.9 \\
\hline 9th grade & 243 & 30.5 \\
\hline I0th grade & 41 & 5.2 \\
\hline \multirow{2}{*}{\multicolumn{3}{|c|}{$\begin{array}{l}\text { Perform less than } \\
\text { expected result }\end{array}$}} \\
\hline & & \\
\hline Yes & 354 & 44.5 \\
\hline No & 441 & 55.4 \\
\hline \multicolumn{3}{|l|}{ Residency } \\
\hline Urban & 517 & 65.1 \\
\hline Rural & 278 & 34.9 \\
\hline \multicolumn{3}{|l|}{ Living with } \\
\hline Alone & 55 & 6.9 \\
\hline Parents & 534 & 67.1 \\
\hline Relatives & 206 & 25.9 \\
\hline \multicolumn{3}{|l|}{ Financial shortage } \\
\hline Yes & 496 & 62.4 \\
\hline No & 299 & 37.6 \\
\hline
\end{tabular}

Note: *Others: only Jesus, Jehovah witness.

than the face-to-face interview employed in this study. Another cause could be socioeconomic, cultural, or environmental differences.

However, the current study's prevalence was higher than previous research done in Canada $39.5 \%, 33,43$ Malaysia $30.7 \%,{ }^{42}$ China $27 \%,{ }^{44}$ Croatia $19.4 \%,{ }^{45}$ Ethiopia $21.2 \%{ }^{6}$ Ethiopia among Addis Ababa students reported $51.3 \%,{ }^{8}$ Gondar $46.3 \%,{ }^{46}$ European students $47 \%{ }^{47}$ and Pakistan $48 \%{ }^{48}$ The difference could be a possible explanation for the observed differences in
Table 2 Characteristics of COVID Related, Psychosocial, Clinical and Behavioral Factors of Participants Among Students from Conflict Affected Setting in South Ethiopia, 202I ( $n=795)$

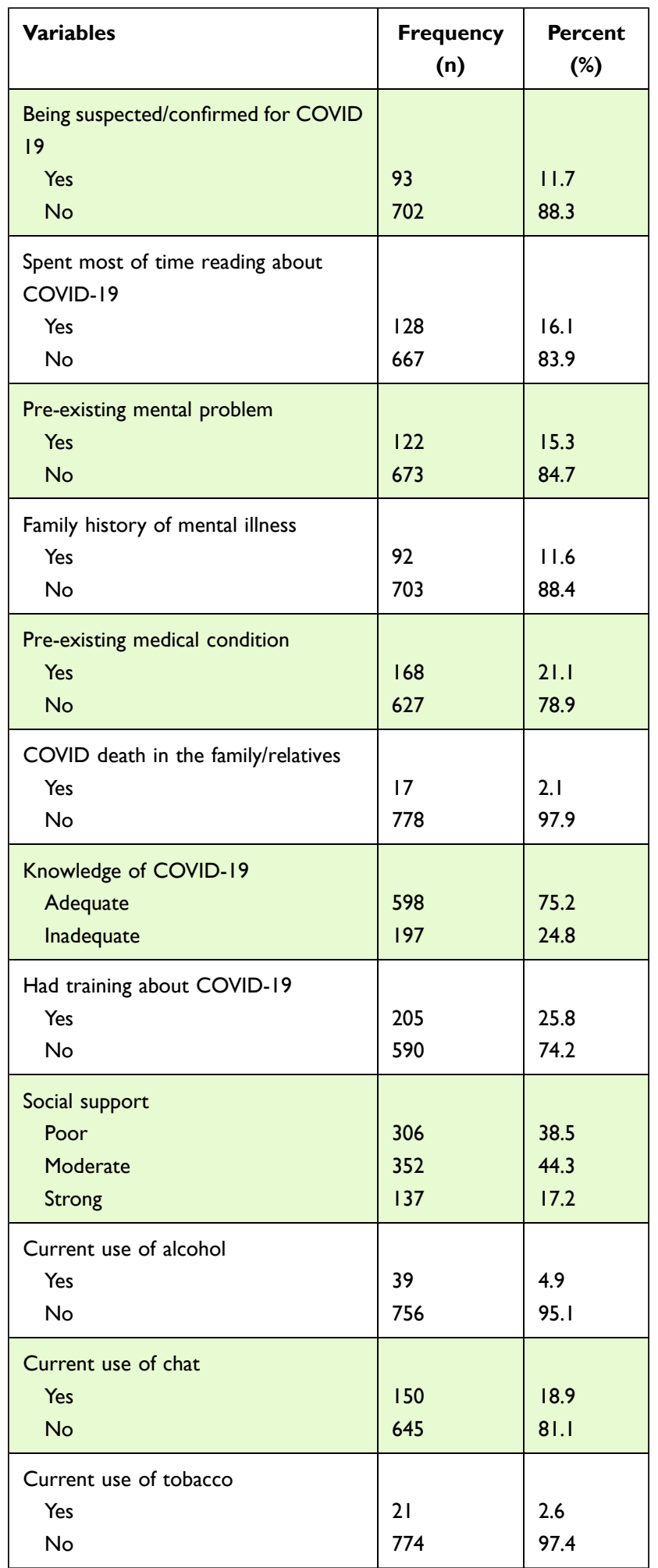

tool, socio-economic, environmental and study design (for instance, an 8 wave longitudinal study was used in 
Conflict and trauma related events

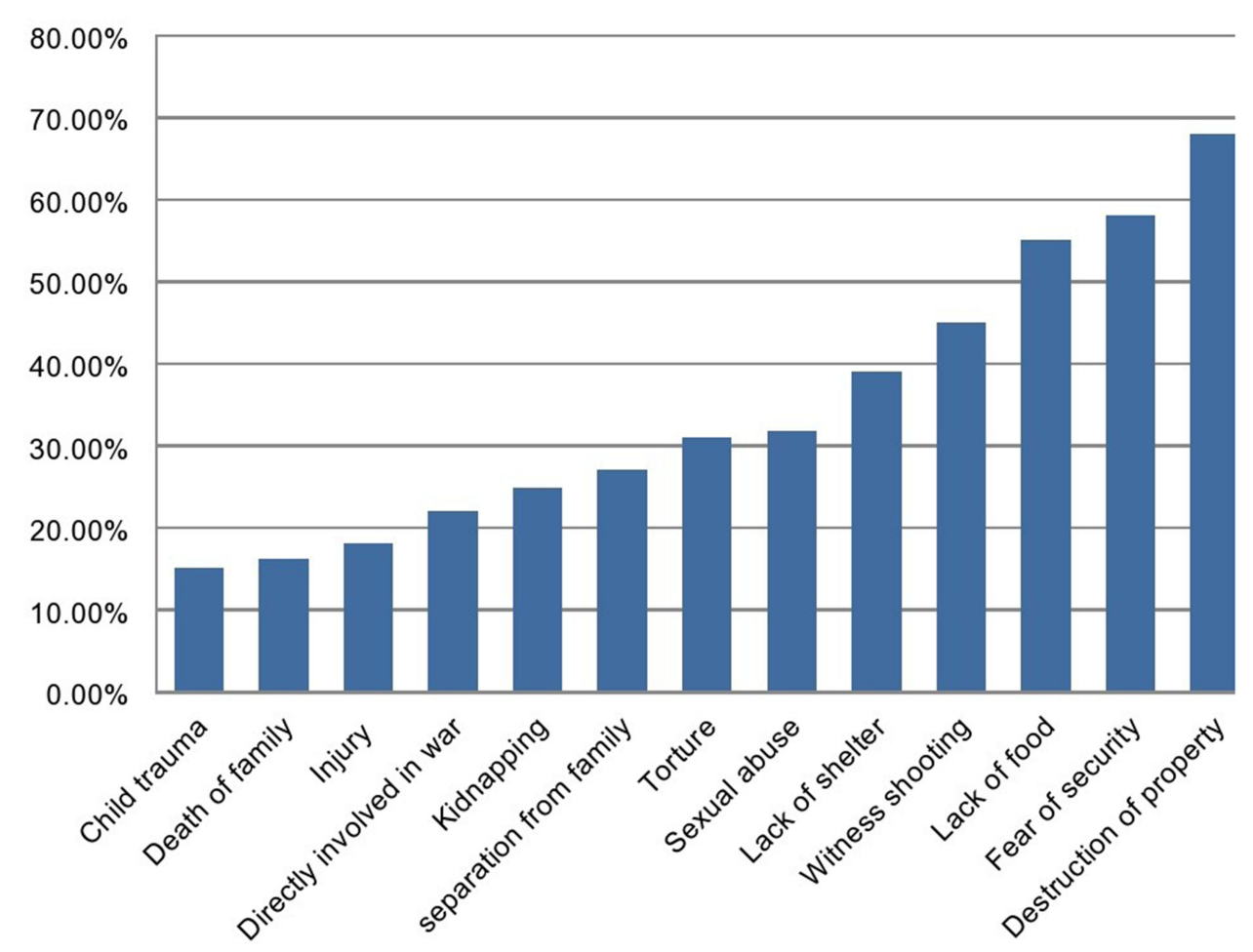

Figure I Conflict and trauma-related events among students from conflict affected setting in south Ethiopia, 2021 ( $\mathrm{n}=795)$.

Croatia, whereas in this study cross-sectional study was used). This study was conducted among students from conflict-affected settings during the era of COVID-19, but the above studies did not include specific students from conflict affected settings. The level of knowledge and perception about COVID-19, stress coping abilities of students, course load, educational delivery system and might be different among students from each country.

When compared to their counterparts, those who had conflict-related sexual abuse were 4.1 times more likely to experience mental distress. The explanation for this could be that sexual violence in conflict is not limited to rape, and conflict-related sexual violence does not end with the end of the conflict. In conflict settings, rates of intimate partner violence are considerably higher, in addition to the rate of wartime rape and sexual violence done by those outside the house. ${ }^{49}$ Sexual and other forms of genderbased violence can have a variety of negative repercussions for survivors, including social implications and poor health. ${ }^{50}$ In survivors of sexual and gender-based violence in areas of armed conflict, a study indicated a significant prevalence of psychological distress and other mental problems. Anxiety disorders (including Posttraumatic Stress Disorder (PTSD), major depressive disorder, medically unexplained problems, substance use disorders, and suicidal ideation are among the mental disorders reported. ${ }^{51}$

Survivors who witnessed shootings of individuals around them were 3.49 times more likely to experience mental distress than those who did not witness shootings of people during the conflict/war. When exposed to or witnessing a terrifying situation, people, like other creatures, become apprehensive or afraid. The level of anxiety or distress varies. Survivors of the shooting may want to avoid the area where the incident occurred, as well as any surrounding contexts, such as grocery stores, if the shooting occurred in one. A survivor may develop posttraumatic stress disorder in a worst-case situation. The consequences can be terrible when students are involved in trauma, such as in a mass shooting. Survivors of mass shootings are at risk of developing PTSD at a rate of up to $36 \%$. Depression, another devastating psychiatric disorder, affects up to $80 \%$ of patients with PTSD. Survivors of mass shootings may also develop survivor's guilt, which is 
Table 3 Bi-Variable and Multivariable Logistic Regression Analysis Showing an Association Between Factors and Mental Distress Among Students from Conflict Affected Setting in South Ethiopia, 2021 ( $n=795)$

\begin{tabular}{|c|c|c|c|c|}
\hline \multirow[t]{2}{*}{ Explanatory Variables } & \multicolumn{2}{|c|}{ Mental Distress } & \multirow[t]{2}{*}{ COR, $(95 \% \mathrm{Cl})$} & \multirow[t]{2}{*}{ AOR $(95 \% \mathrm{Cl})$} \\
\hline & Yes & No & & \\
\hline \multicolumn{5}{|l|}{ Sex } \\
\hline Male & 185 & 227 & 1 & 1 \\
\hline Female & 275 & 108 & $3.12[1.84,4.37]$ & $3.01[1.6 \mathrm{I}, 5.44]^{* * *}$ \\
\hline \multicolumn{5}{|l|}{ Age } \\
\hline $15-19$ & 318 & 85 & $3.55[1.32,3.99]$ & $2.9[0.17,3.4]$ \\
\hline $20-24$ & 166 & 72 & $2.1[2.18,4.33]$ & $1.9[0.89,3.1]$ \\
\hline$\geq 25$ & 79 & 75 & I & 1 \\
\hline \multicolumn{5}{|l|}{ Residency } \\
\hline Urban & 329 & 185 & $1.58[1.18,2.14]$ & $1.41[0.56,3.04]$ \\
\hline Rural & 147 & $|3|$ & 1 & 1 \\
\hline \multicolumn{5}{|l|}{ Social support } \\
\hline Poor & 102 & 204 & $4.1[2.49,6.29]$ & $3.33[0.95,5.70]$ \\
\hline Moderate & 56 & 296 & $\mathrm{I} .54[0.87,2.50]$ & $1.34[0.76,2.38]$ \\
\hline Strong & 15 & 122 & 1 & 1 \\
\hline \multicolumn{5}{|l|}{ Pre-existing medical condition } \\
\hline Yes & 111 & 57 & $1.45[0.95,2.25]$ & $1.26[0.76,2.08]$ \\
\hline No & 359 & 268 & 1 & 1 \\
\hline \multicolumn{5}{|l|}{ School performance } \\
\hline Poor & 242 & 112 & $2.44[1.92,3.44]$ & $2.1[1.65,3.67]^{* * *}$ \\
\hline Good & 207 & 234 & I & I \\
\hline \multicolumn{5}{|l|}{ Conflict related sexual abuse } \\
\hline Yes & 74 & 99 & $3.26[2.05,5.04]$ & $4.06[2.37,6.94] * *$ \\
\hline No & 116 & 506 & I & 1 \\
\hline \multicolumn{5}{|l|}{ Knowledge of COVID-19 } \\
\hline Adequate & 122 & 476 & $0.68[0.55,2.64]$ & I.I $[0.87,2.19]$ \\
\hline Inadequate & 54 & 143 & I & I \\
\hline \multicolumn{5}{|l|}{ Threat to security and safety } \\
\hline Yes & 138 & 323 & $1.67[1.04,2.63]$ & $2.23[1.29,3.87] * *$ \\
\hline No & 68 & 266 & I & 1 \\
\hline \multicolumn{5}{|l|}{ Witnessed shooting } \\
\hline Yes & 292 & 66 & $3.69[2.54,5.39]$ & $3.49[2.7,5.89]^{* * *}$ \\
\hline No & 238 & 199 & 1 & I \\
\hline
\end{tabular}

Notes: $* * p<0.01, * * * p<0.001$.

the feeling that they failed others who died or who did not do enough to help them, or just guilt for surviving. ${ }^{52,53}$

When it came to student achievement, those who did poorly in school were 2.1 times more likely to experience mental distress than those who did well. Early school dropout has been associated with substance addiction, depression, and externalizing challenges in studies on the impact of educational accomplishment and academic performance on mental health in the younger population, which mostly comprises adolescents (such as students). ${ }^{54}$ Furthermore, academic performance in students has been linked to male suicide. ${ }^{55}$ In a recent Swedish study, poor academic performance was linked to depression in young adulthood. ${ }^{56}$ This could put you at a high risk of developing mental illness.

Furthermore, having a danger to one's security and safety was linked to mental distress in this study. When compared to their counterparts, those who faced a danger 
to their security and safety were 2.23 times more likely to experience mental distress. The explanation for this could be that military use of schools disrupts children's education and destroys school infrastructure. School attendance and educational quality may suffer as a result of fear and violence, and schools may even close. Effective teaching and learning require a safe and secure environment. A safe and secure environment is necessary for effective teaching and learning. In the context of violence and terror, school attendance and education quality may decline, and schools may even close due to the danger of attack. This has an impact on students' emotional health as well as their academic performance. ${ }^{57-59}$

Being female was found to be one of the strongest predictors of mental distress. Females were three times more likely than males to experience mental distress. According to the study, girls are disproportionately harmed because they are more vulnerable to sexual violence on school grounds or are kept at home by their parents when the security situation worsens. Females' education outcomes in conflict-affected countries are often worse than boys', according to research, and girls frequently drop out after a school is occupied. Fear of sexual abuse in the school is one of the reasons. ${ }^{60}$ Women are disproportionately disadvantaged in terms of personal safety, resource access, and human rights during times of war, and gender inequality is reinforced. If girls live in a conflict-affected country, they are nearly two and a half times more likely to be out of school, and adolescent girls are nearly $90 \%$ more likely to be out of secondary school. ${ }^{61}$ This all together worsens the mental health of students in the conflict setting.

\section{The Study's Strengths and Limitations}

This is the first research of its kind in Ethiopia, involving students from conflict-affected areas. Second, it added important variables that had previously been excluded from earlier studies. One of the study's merits was that it used an updated standardized and validated instrument to measure the outcome variable. One of the drawbacks was that only students from conflict-affected areas of south Ethiopia were included.

\section{Conclusion}

High rate of mental distress was found among students from conflict affected setting. Being female, treat for security and safety, witnessed shooting, conflict-related sexual abuse, perform less than expected were all significant indicators of mental distress. Therefore, the ministry of health, ministry of education and humanitarian organizations should work collaboratively in providing consistent school-based psychosocial support and appropriate intervention for students.

\section{Abbreviations}

COVID, Corona Virus Disease; IDMC, Internal Displacement Monitoring Center; K10, Kessler Psychological Distress scale; PTSD, Post-Traumatic Stress Disorder.

\section{Data Sharing Statement}

Upon reasonable request, the corresponding author made the data for this study available.

\section{Ethical Approval}

The ethical review board of Dilla University's college of health science and medicine provided ethical approval number DU/225/7/111 for all data collection techniques, as well as the Helsinki Declaration. Each school director provided a formal letter of permission. Following an explanation of the study's goal, we gathered written informed consent from individuals aged 18 and up, as well as assent (parental informed consent) from those under the age of 18. All the information was kept private.

\section{Acknowledgments}

The author of this study would like to express his gratitude to the entire employees of the university administration. Dilla University's Department of Psychiatry, College of Health and Medicine, deserves our gratitude. Finally, I would want to express my gratitude to all the participants for their cooperation and assistance in gathering the essential information.

\section{Author Contributions}

All authors made a significant contribution to the work reported, whether that is in the conception, study design, execution, acquisition of data, analysis and interpretation, or in all these areas; took part in drafting, revising or critically reviewing the article; gave final approval of the version to be published; have agreed on the journal to which the article has been submitted; and agree to be accountable for all aspects of the work. 


\section{Funding}

There is no funding to report.

\section{Disclosure}

There are no competing interests declared by the authors.

\section{References}

1. Charlson F, van Ommeren M, Flaxman A, Cornett J, Whiteford H, Saxena S. New WHO prevalence estimates of mental disorders in conflict settings: a systematic review and meta-analysis. Lancet 2019;394(10194):240-248. doi:10.1016/S0140-6736(19)30934-1

2. Council NR. Global Overview 2014: People Internally Displaced by Conflict and Violence-Democratic Republic of the Congo. Vol. 14. Internal Displacement Monitoring Centre (NRC/IDMC); 2016.

3. Belay DG. COVID-19, distance learning and educational inequality in Rural Ethiopia. Pedagogical Res. 2020;5(4):em0082. doi:10.29333/pr/ 9133

4. Mengistie TA. Impacts of COVID-19 on the Ethiopian education system. Sci Insigt Educ Front. 2020;6:569-578. doi:10.15354/ sief.20.or011

5. Tadesse W, Mihret S, Biset G, Muluneh A. Psychological impacts of COVID-19 among college students in Dessie town, Amhara region, Ethiopia; cross-sectional study. Research Square. 2020;10. doi:10.21203/rs.3.rs-38100/v1

6. Aylie NS, Mekonen MA, Mekuria RM. The psychological impacts of COVID-19 pandemic among university students in Bench-Sheko Zone, South-west Ethiopia: a community-based cross-sectional study. Psychol Res Behav Manag. 2020;13:813. doi:10.2147/PRBM. S275593

7. Mekonen EG, Workneh BS, Ali MS, Muluneh NY. The psychological impact of COVID-19 pandemic on graduating class students at the University of Gondar, northwest Ethiopia. Psychol Res Behav Manag. 2021;14:109. doi:10.2147/PRBM.S300262

8. Simegn W, Dagnew B, Yeshaw Y, Yitayih S, Woldegerima B, Dagne H. Depression, anxiety, stress and their associated factors among Ethiopian University students during an early stage of COVID-19 pandemic: an online-based cross-sectional survey. PLoS One. 2021;16(5):e0251670. doi:10.1371/journal.pone.0251670

9. Sahile AT, Ababu M, Alemayehu S, et al. Prevalence and severity of depression, anxiety, and stress during pandemic of COVID-19 among college students in Addis Ababa, Ethiopia, 2020: a cross sectional survey. Int J Clin Exp Med Sci. 2020;6:126.

10. Baird M. Service delivery in fragile and conflict-affected states; 2011.

11. Jones GA, Rodgers D. The world bank's world development report 2011 on conflict, security and development: a critique through five vignettes. J Int Dev. 2011;23:980-995. doi:10.1002/jid.1826

12. Smith A. The Influence of Education on Conflict and Peace Building, Background Paper Prepared for the Education for All Global Monitoring Report 2011 the Hidden Crisis: Armed Conflict and Education. Paris: UNESCO; 2010.

13. UNICEF., Children UNOotSRotS-Gf, Conflict A. Machel Study 10-Year Strategic Review: Children and Conflict in a Changing World; 2009.

14. Slone M, Mann S. Effects of war, terrorism and armed conflict on young children: a systematic review. Child Psychiatry Hum Dev. 2016;47(6):950-965. doi:10.1007/s10578-016-0626-7

15. Miller KE, Rasmussen A. War exposure, daily stressors, and mental health in conflict and post-conflict settings: bridging the divide between trauma-focused and psychosocial frameworks. Soc Sci Med. 2010;70(1):7-16. doi:10.1016/j.socscimed.2009.09.029

16. Lee C, Nguyen AJ, Russell T, Aules Y, Bolton P. Mental health and psychosocial problems among conflict-affected children in Kachin State, Myanmar: a qualitative study. Confl Health. 2018;12(1):1-11. doi:10.1186/s13031-018-0175-8
17. Murthy RS, Lakshminarayana R. Mental health consequences of war: a brief review of research findings. World Psychiatry. 2006;5:25.

18. Hasanović M. Psychological consequences of war-traumatized children and adolescents in Bosnia And Herzegovina. Acta Med Acad. 2011;40(1):45-66. doi:10.5644/ama2006-124.8

19. Roberts B, Ezard N. Why are we not doing more for alcohol use disorder among conflict-affected populations? Addiction. 2015;110 (6):889-890. doi:10.1111/add.12869

20. Romeo A, Benfante A, Castelli L, Di Tella M. Psychological distress among Italian university students compared to general workers during the COVID-19 pandemic. Int J Environ Res Public Health. 2021;18(5):2503. doi:10.3390/ijerph18052503

21. Wathelet M, Duhem S, Vaiva G, et al. Factors associated with mental health disorders among university students in France confined during the COVID-19 pandemic. JAMA Netw Open. 2020;3(10):e2025591. doi:10.1001/jamanetworkopen.2020.25591

22. Elmer T, Mepham K, Stadtfeld C, Capraro V. Students under lockdown: comparisons of students' social networks and mental health before and during the COVID-19 crisis in Switzerland. PLoS One. 2020;15(7):e236337. doi:10.1371/journal. pone. 0236337

23. Monfared A, Akhondzadeh L, Soleimani R, Maroufizadeh S, Pouy S, Asgari F. Psychological distress and coping strategies among clinicians and medical students during the COVID-19 pandemic: a Cross-sectional Study in Guilan, Iran. Shiraz E Medical J. 2021;22 (5). doi:10.5812/semj.109764

24. Dhonncha EN, Murphy M. Learning new ways of teaching and assessment: the impact of COVID-19 on undergraduate dermatology education. Clin Exp Dermatol. 2020, doi:10.1111/ced.14364

25. Akinyemi OO, Owoaje ET, Ige OK, Popoola OA. Comparative study of mental health and quality of life in long term refugees and host populations in Oru-Ijebu, Southwest Nigeria. BMC Res Notes. 2012;5 (1):1-9. doi:10.1186/1756-0500-5-394

26. Priebe S, Gavrilovic J, Bremner S, et al. Course of post-traumatic stress disorder following war in the Balkans: 1-year follow-up study. Psychol Med. 2013;43(9):1837-1847. doi:10.1017/ S0033291712002681

27. Kazmi SSH, Hasan DK, Talib S, Saxena S. COVID-19 and Lockdown: A Study on the Impact on Mental Health. SSRN 3577515; 2020.

28. Farhood L, Dimassi H. Symptom Prevalence of PTSD, Anxiety, Depression, Effect of Exposure and Mediating Factors on a Population from Southern Lebanon. American Univ Beirut (Lebanon); 2006.

29. Browne G, Hemsley M. Consumer participation in mental health in Australia: what progress is being made? Australas Psychiatry. 2008;16(6):446-449. doi:10.1080/10398560802357063

30. Hobfoll SE, Canetti-Nisim D, Johnson RJ, Palmieri PA, Varley JD, Galea S. The association of exposure, risk, and resiliency factors with PTSD among Jews and Arabs exposed to repeated acts of terrorism in Israel. J Trauma Stress. 2008;21:9-21. doi:10.1002/ jts.20307

31. Fortes S, Lopes C, Villano LAB, Campos MR, Gonçalves DA, Mari JJ. Common mental disorders in Petrópolis-RJ: a challenge to integrate mental health into primary care strategies. Rev Bras Psiquiatr. 2011;33:150-156. doi:10.1590/S1516-44462011000 200010

32. Steel Z, Chey T, Silove D, Marnane C, Bryant RA, Van Ommeren M. Association of torture and other potentially traumatic events with mental health outcomes among populations exposed to mass conflict and displacement: a systematic review and meta-analysis. JAMA. 2009;302(5):537-549. doi:10.1001/jama.2009.1132

33. Hamaideh SH. Alexithymia among Jordanian university students: its prevalence and correlates with depression, anxiety, stress, and demographics. Perspect Psychiatr Care. 2017;54:274-280. doi:10.1111/ppc. 12234 
34. Kaya E, Karadag Caman O, Kilic C, Uner S. Need for and barriers to accessing mental health care among refugees in Turkey: a mixed methods study. Eur J Public Health. 2018;28(suppl_4):cky213. 453. doi:10.1093/eurpub/cky212.453

35. Salman M, Asif N, Mustafa ZU, et al. Psychological impairment and coping strategies during the COVID-19 pandemic among students in Pakistan: a cross-sectional analysis. Disaster Med Public Health Prep. 2020:1-7. doi:10.1017/dmp.2020.397

36. Dessie Y, Ebrahim J, Awoke T. Mental distress among university students in Ethiopia: a cross sectional survey. Pan Afr Med J. 2013;15:95. doi:10.11604/pamj.2013.15.95.2173

37. Andersen L, Grimsrud A, Myer L, Williams D, Stein D, Seedat S. The psychometric properties of the K10 and K6 scales in screening for mood and anxiety disorders in the South African Stress and Health study. Int J Methods Psychiatr Res. 2011;20(4):215-223. doi:10.1002/mpr.351

38. Kessler RC, Andrews G, Colpe LJ, et al. Short screening scales to monitor population prevalences and trends in non-specific psychological distress. Psychol Med. 2002;32:959-976.

39. Tesfaye M, Hanlon C, Wondimagegn D, Alem A. Detecting postnatal common mental disorders in Addis Ababa, Ethiopia: validation of the Edinburgh postnatal depression scale and Kessler scales. J Affect Disord. 2010;122(1-2):102-108. doi:10.1016/j.jad.2009.06.020

40. Abiola T, Udofia O, Zakari M. Psychometric properties of the 3-item Oslo social support scale among clinical students of Bayero University Kano, Nigeria. Malays J Psychiatry. 2013;22:32-41.

41. Kumar B, Shah MAA, Kumari R, Kumar A, Kumar J, Tahir A. Depression, anxiety, and stress among final-year medical students. Cureus. 2019;11:e4257.

42. Okafor N. Socio-demographic characteristics and other factors associated with depressive illness among medical students at the University of Port Harcourt; 2020.

43. Othman N, Ahmad F, El Morr C, Ritvo P. Perceived impact of contextual determinants on depression, anxiety and stress: a survey with university students. Int J Ment Health Syst. 2019;13(1):1-9. doi:10.1186/s13033-019-0275-X

44. Li Y, Wang Y, Jiang J, et al. Psychological distress among health professional students during the COVID-19 outbreak. Psychol Med. 2020;1-3. doi:10.1017/S0033291720001555.

45. Vulić-Prtorić A, Selak MB, Sturnela P. The psychological distress in students during the COVID-19 crisis: an 8-wave longitudinal study; 2020.

46. Akalu TY, Gelaye KA, Bishaw MA, et al. Depression, anxiety, and stress symptoms and its associated factors among residents of Gondar Town during the early stage of COVID-19 pandemic. Risk Manag Healthc Policy. 2021;14:1073. doi:10.2147/RMHP.S296796

47. Habihirwe P, Porovecchio S, Bramboiu I, et al. Depression, anxiety and stress among college students in three European countries. Eur J Public Health. 2018;28(suppl_4):cky214. 026. doi:10.1093/eurpub/ cky214.026
48. Syed A, Ali SS, Khan M. Frequency of depression, anxiety and stress among the undergraduate physiotherapy students. Pak J Med Sci. 2018;34:468. doi:10.12669/pjms.342.12298

49. Kelly JT, Betancourt TS, Mukwege D, Lipton R, Vanrooyen MJ. Experiences of female survivors of sexual violence in eastern Democratic Republic of the Congo: a mixed-methods study. Conf Health. 2011;5(1):1-8. doi:10.1186/1752-1505-5-25

50. Sherrer MV. The role of cognitive appraisal in adaptation to traumatic stress in adults with serious mental illness: a critical review. Trauma Violence Abuse. 2011;12(3):151-167. doi:10.1177/152483801 1404254

51. Johnson K, Asher J, Rosborough S, et al. Association of combatant status and sexual violence with health and mental health outcomes in postconflict Liberia. JAMA. 2008;300:676-690. doi:10.1001/ jama.300.6.676

52. Paolini A. School shootings and student mental health: role of the school counselor in mitigating violence. Vistas Online. 2015;90:1-15.

53. Metzl JM, MacLeish KT. Mental illness, mass shootings, and the politics of American firearms. Am J Public Health. 2015;105 (2):240-249. PMCID: PMC4318286. doi:10.2105/ AJPH.2014.302242

54. Esch P, Bocquet V, Pull C, et al. The downward spiral of mental disorders and educational attainment: a systematic review on early school leaving. BMC Psychiatry. 2014;14(1):1-13. doi:10.1186/ s12888-014-0237-4

55. Gunnell D, Löfving S, Gustafsson J-E, Allebeck P. School performance and risk of suicide in early adulthood: follow-up of two national cohorts of Swedish schoolchildren. J Affect Disord. 2011;131(1-3):104-112. doi:10.1016/j.jad.2011.01.002

56. Wallin AS, Koupil I, Gustafsson J-E, Zammit S, Allebeck P, Falkstedt D. Academic performance, externalizing disorders and depression: 26,000 adolescents followed into adulthood. Soc Psychiatry Psychiatr Epidemiol. 2019;54(8):977-986. doi:10.1007/ s00127-019-01668-z

57. Petener Z. Asymmetric warfare - not every war has to end? Secur Def $Q$. 2016;11(2):30-44. doi:10.35467/sdq/105400

58. Bart GR. The ambiguous protection of schools under the law of war-time for parity with hospitals and religious buildings. Geo J Int'L L. 2008;40:405.

59. Bart GR. The ambiguous protection of schools under the law of war: time for parity with hospitals and religious buildings'(2009). Georget J Int Law. 2009;40:405.

60. Ferris E, Winthrop R. Education and displacement: assessing conditions for refugees and internally displaced persons affected by conflict. Background paper for the EFA Global Monitoring Report 2011 The hidden crisis: Armed conflict and education; 2010.

61. Ossiannilsson E. Challenges and opportunities for active and hybrid learning related to UNESCO post 2015. In: Handbook of Research on Active Learning and the Flipped Classroom Model in the Digital Age. IGI Global; 2016:333-351.
Neuropsychiatric Disease and Treatment

\section{Publish your work in this journal}

Neuropsychiatric Disease and Treatment is an international, peerreviewed journal of clinical therapeutics and pharmacology focusing on concise rapid reporting of clinical or pre-clinical studies on a range of neuropsychiatric and neurological disorders. This journal is indexed on PubMed Central, the 'PsycINFO' database and CAS, and is the official journal of The International Neuropsychiatric Association (INA). The manuscript management system is completely online and includes a very quick and fair peer-review system, which is all easy to use. Visit http://www.dovepress.com/testimonials.php to read real quotes from published authors. 